\section{Clinico-Socio Demographic Profile of Children with Autism Spectrum Disorders from a Tertiary Care Hospital in Kashmir, India}

\section{Abstract}

Background: In spite of advances in assessment and management of patients with Autism Spectrum Disorders (ASDs) in west, developing countries including India are lagging far behind in child psychiatry, let alone ASDs. The aims of our study were to find the socio-demographic and clinical profile of children with ASDs in a child psychiatry unit.

Methods and Materials: This was a Cross sectional observational descriptive study conducted in Outpatient child psychiatry clinic. Semi-structured questionnaire was used to record the socio-demographic status. The diagnosis of ASDs was made on the basis of Diagnostic and Statistical Manual of Mental Disorders, 4th Edition, Text Revision (DSM IV-TR) after a thorough clinical assessment which was also confirmed by consultant in charge child psychiatry. Intelligence quotient was assessed by clinical psychologist. Descriptive statistical analysis was done and presented as frequencies and percentages.

Results: A total of 55 patients were diagnosed with ASDs. Most of the patients were less than 9 years with $52.73 \%$ in $4-7$ years age group and $21.82 \%$ in $7-9$ year age group. Males (78.18\%) out-numbered females. $52.73 \%$ belonged to Nuclear Family and $63.63 \%$ were from rural background. $70.91 \%$ were staying at home. Autism was the most frequent diagnosis in $61.82 \%$ of the patients followed by Pervasive Developmental Disorder not otherwise specified (PDD NOS) in $30.91 \%$. Co-morbid mental retardation (MR) was present in $47(85.45 \%$ ) of our subjects.

Conclusion: $10.4 \%$ of children and adolescents with psychiatric disorders were having ASDs with autistic disorder and PDD NOS representing more than $90 \%$ of these cases. Despite the growing global attention for inclusive education to these children, only $3 \%$ of our cases were receiving inclusive education and about $70 \%$ of cases were staying at home.

Keywords: Autism spectrum disorders; Inclusive education; Tertiary care hospital

\section{Bilal Ahmad Bhat*, Arshad MOHD Hussain, Wasim Qadir and Shabir Ahmad Dar}

Government Medical College Srinagar, Srinagar, Jammu and Kashmir, India

\section{*Corresponding author: Bilal Ahmad Bhat, M.D. \\ झ bilalahmadbhat69@gmail.com}

Government Medical College Srinagar, Srinagar, Jammu and Kashmir, India.

Tel: +917006351640

Citation: Bhat BA, Hussain AM, Qadir W, Dar SA (2019) Clinico-Socio Demographic Profile of Children with Autism Spectrum Disorders from a Tertiary Care Hospital in Kashmir, India. J Child Dev Disord. Vol.5 No.2:5

\section{Introduction}

Pervasive developmental disorders (PDDs) also known as Autism Spectrum Disorders (ASDs) are a group of neurodevelopmental disorders in which there is impaired development in social, communicative and cognitive abilities [1]. Although these disorders are usually detected in early childhood but the time at which these disorders are diagnosed is much later than the time of onset of these disorder [2-4]. In addition, there may be a long duration between the acknowledgement of early symptoms and signs of these disorders by parents and the diagnosis of these disorders [5]. This is further complicated by the fact that there are no early signs of ASDs which are specific to these disorders, making it hard to recognize and diagnose these disorders at early stage [6]. In DSM IV-TR, the five disorders in the category of ASDs are Autism, childhood disintegrative disorder (CDD), Rett's disorder, Asperger syndrome (AS), and pervasive developmental disorder-not otherwise specified (PDD-NOS) $[1,7,8]$. Autism is characterized by deficits in reciprocal social interaction and communication, and unusual and repetitive 
Stereotypic behaviour [9]. Although certain set of behaviors define autism, but the children suffering from it may exhibit these behaviors in any combination with variable degree of severity [9]. Furthermore, the difference among the different disorders under PDDs is also in relation to presence of these impairments and behaviors as well as their severity [9]. In previous studies, autistic disorder, AS, and PDD-NOS were difficult to differentiate from each other with overlapping criteria for AS and autistic disorder, and a consistent distinction between the different ASDs is uncommon [10-12]. The prevalence of ASDs has been shown to increase progressively since 1985 with an estimate ranging from $0.07 \%$ to $2.64 \%$ [13-15]. A combination of many factors including greater awareness in public, diagnosis at lower age, better ascertaining of cases, substituting diagnosis, and changes in the diagnostic models and corresponding diagnostic criteria have been attributed to these prevalence changes of ASDs [15]. However, an estimate of 0.6 to $0.7 \%$ or one child in about 150 children can be confidently derived from the recent studies on prevalence of autism spectrum disorders [15]. Toddlers at risk of ASDs are not uncommon in India as a recent study found that between the age of 16-24 months, $5.5 \%$ were at risk on culturally adapted Modified Checklist for Autism in Toddlers-Revised (MCHAT-R) and $2.7 \%$ on shortened 7-question M-CHAT R ("Best Seven") [16]. In addition, siblings of children with ASDs should be routinely screened for the presence of ASDs as prevalence of ASDs in siblings of Indian children with Autism in a recent study was $4.97 \%$ [17]. Being a complex neurodevelopmental disorder and in the absence of a biologic markers, ASDs are diagnosed based on behaviors instead of medical tests and requires the examining clinician to have unique skills and experience in identifying those behavioral phenotype [18]. Diagnostic criteria for the ASDs are described in the Diagnostic and Statistical Manual of Mental Disorders, Fourth Edition, Text Revision (DSM-IV-TR) [19]. It is believed by many researchers that the shared social impairment is the hallmark feature of the ASDs that distinguishes them from other childhood disorders [20-22]. Although the beneficial effects of early diagnosis and intervention have been demonstrated by evidence, the opportunity for specialized services is missed by many children with ASDs [23-25]. For the children suffering from these disorders and their care givers to be benefitted, it is essential to diagnose ASDs as early as possible [23]. Moreover, diagnosis is also essential to get an access to services and specially designed intervention programs. In addition, providing appropriate information to parents will make them more intelligent and informed consumers of services on behalf of their child. Unfortunately we don't have any specialized center for these children in our part of the world. Our department of psychiatry started a child psychiatry clinic in May 2014 and the present study was carried out in the same center as a preliminary study with an aim to find the socio-demographic and clinical profile of children with ASDs.

\section{Material and Methods}

This was a cross sectional observational descriptive study which was conducted among the patients attending the Outpatient service of the child psychiatry clinic of Postgraduate Department of Psychiatry over a period of one and half year, from Feb. 2015 to June 2016. The study was approved by the institutional ethical committee. Children of both the sexes with age 1 to 16 years whose parent/ guardian gave the consent and who were diagnosed with pervasive developmental disorders were included in the study. Written informed consent from the parent/ guardian was taken in a simple and easily understandable unambiguous language. A semi-structured questionnaire consisting of age, sex, residence, family type and occupation was used to record the socio-demographic status of the children attending the clinic. The psychiatric morbidity of the children was assessed after a thorough clinical assessment by a senior resident of child psychiatry clinic. Intelligence quotient (IQ) was assessed by clinical psychologist. The diagnosis was made on the basis of DSM-IV TR criteria which were later confirmed by the consultant in-charge child psychiatry clinic [19]. The data about various parameters was entered into Microsoft Excel. Descriptive analysis was carried out using Statistical Package for the Social Sciences version 20.0. Continuous data were represented as mean and standard deviation. Categorical data were represented in the form of frequencies and percentages. Chi-square was used as test of significance. $\mathrm{P}<0.05$ was considered as statistically significant.

\section{Results}

This study included 55 children and adolescents with ASDs. The mean age of our study population was $6.50 \pm 3.06$ years, with a minimum age of 2 years and a maximum of 16 years. Of these 55 children and adolescents, 7 (12.73\%) patients were in 1-3 year age group, 29 (52.73\%) patients were in 4-6 year age group, 12 (21.82\%) patients were in 7-9 year age group, $3(5.45 \%)$ patients were in 10-12 year age group whereas $4(7.27 \%)$ patients were in 13-16 year age group. Using chi-square, the differences in number of patients within different age groups was statistically significant $(p=0.0001)$. Males out-numbered females by an approximate ratio of $3.6: 1$ with $43(78.18 \%)$ males and 12 (21.82\%) females. 29 patients $(52.73 \%)$ belonged to Nuclear Family whereas $26(47.27 \%)$ belonged to Extended families. 35 of the patients $(63.63 \%)$ were from rural background where as $20(36.37 \%)$ were from urban background. 39 patients $(70.91 \%)$ were not involved with a particular occupation and were staying at home. 13 of the patients $(37.14 \%)$ were attending a special school/crèche whereas 3 of our patients $(5.45 \%)$ were students (Table 1).

Autism was the most frequent diagnosis occurring in 34 (61.82\%) of the patients followed by Pervasive Developmental Disorder not otherwise specified (PDD-NOS) which occurred in 17 patients (30.91\%). Asperger's Disorder was found in 3 patients $(5.45 \%)$ and 1 patient (1.82\%) had Rett's Syndrome (Table 2 ).

Co-morbid mental retardation (MR) was present in $47(85.45 \%)$ of our subjects. Mild MR (IQ = 50-70) was present in 19(34.55\%) cases, Moderate MR (IQ = 35-49) in $14(25.45 \%)$ cases, Severe MR $(I Q=20-34)$ in $11(20 \%)$ cases and Profound MR $(I Q<20)$ in $3(5.45 \%)$ cases (Table 3 ). 
Table 1 Socio-demographic profile $(\mathrm{N}=55)$.

\begin{tabular}{|c|c|c|c|}
\hline Age in years & Number of patients (\%) & Chi-square & $P$ value \\
\hline $1-3$ & $7(12.73 \%)$ & \multirow{5}{*}{41.273} & \multirow[b]{5}{*}{0.0001} \\
\hline $4-6$ & $29(52.73 \%)$ & & \\
\hline $7-9$ & $12(21.82 \%)$ & & \\
\hline $10-12$ & $3(5.45 \%)$ & & \\
\hline $13-16$ & $4(7.27 \%)$ & & \\
\hline Sex of patient & Number of patients & Chi-square & $P$ value \\
\hline Male & $43(78.18 \%)$ & \multirow[b]{2}{*}{17.47} & \multirow[b]{2}{*}{0.0001} \\
\hline Female & $12(21.82 \%)$ & & \\
\hline Family Type & Number of patients & Chi-square & $P$ value \\
\hline Nuclear & $29(52.73 \%)$ & \multirow[b]{2}{*}{0.164} & \multirow[b]{2}{*}{0.686} \\
\hline Extended & $26(47.27 \%)$ & & \\
\hline Residence & Number of Patients & Chi-square & P value \\
\hline Rural & $35(63.63 \%)$ & \multirow[b]{2}{*}{4.09} & \multirow[b]{2}{*}{0.04} \\
\hline Urban & $20(36.37 \%)$ & & \\
\hline Occupation & Number of Patients & Chi-square & $P$ value \\
\hline Student & $3(5.45 \%)$ & \multirow[b]{4}{*}{63.33} & \multirow[b]{4}{*}{0.0001} \\
\hline Crèche & $4(7.27 \%)$ & & \\
\hline Special School & $9(16.36 \%)$ & & \\
\hline $\mathrm{Nil}$ & $39(70.91 \%)$ & & \\
\hline
\end{tabular}

Table 2 Autism Spectrum Disorders- clinical profile.

\begin{tabular}{|c|c|c|c|}
\hline Diagnosis & $\begin{array}{l}\text { Number of } \\
\text { Patients }\end{array}$ & Chi-square & $P$ value \\
\hline Autism & $34(61.82 \%)$ & & \\
\hline PDD-NOS & $17(30.91 \%)$ & & \\
\hline Asperger's Disorder & $3(5.45 \%)$ & & \\
\hline Rett's Syndrome & $1(1.82 \%)$ & & \\
\hline Total & $55(100 \%)$ & 50.82 & 0.0001 \\
\hline
\end{tabular}

PDD = Pervasive Developmental Disorder; PDD-NOS $=$ Pervasive Developmental Disorder not otherwise specified.

Table 3 Co-morbid Mental Retardation and Intelligence Quotient in PDD $(\mathrm{N}=55)$.

\begin{tabular}{|c|c|}
\hline Intelligence Quotient & Number of Patients \\
\hline Mild MR $(\mathrm{IQ}=50-70)$ & $19(34.55 \%)$ \\
\hline Moderate $\mathrm{MR}(\mathrm{IQ}=35-49)$ & $14(25.45 \%)$ \\
\hline Severe MR $(\mathrm{IQ}=20-34)$ & $11(20 \%)$ \\
\hline Profound $\mathrm{MR}(\mathrm{IQ}<20)$ & $3(5.45 \%)$ \\
\hline Total & $47(85.45 \%)$ \\
\hline
\end{tabular}

$M R=$ Mental Retardation, $I Q=$ Intelligence Quotient

\section{Discussion and Conclusion}

ASDs, a group of neurodevelopmental disorders, is a clinically manifested behavioral syndrome that usually presents in early childhood [26]. The core symptoms of ASDs include absent or abnormal reciprocated interpersonal and emotional interactions, impaired language and communication, and repetitive/ stereotypic pattern of behavior [19]. Populations worldwide are affected by this condition [27]. Current burden of ASDs worldwide is implicit. Since the year 2000, most of the studies conducted across the globe have shown an estimate prevalence of 17/10,000 for autistic disorder and 62/10,000 for all ASDs [28]. In both DSMIV and International Classification of Mental and Behavioural Disorders-10, ASDs is the diagnostic catagory for"autism like"disorders, which includes Autistic Disorder, Asperger Syndrome, childhood disintegrative disorder, Rett's syndrome and Pervasive Developmental Disorder-Not Otherwise Specified $[19,29]$. Indian research on ASDs has been largely confined to hospital settings or selective settings for autistic children [30-33]. Like other parts of India, prevalence of ASDs from our state has not been studied yet. Out of 529 patients who visited our clinic during the study period, 55 (10.4\%) patients were diagnosed with ASDs. Studies from India, other countries in the sub-continent and west have also found lower proportion with ASDs among the children visiting child psychiatry outpatient [34-37]. One reason for higher rate of ASDs in our study could be that our clinic is the only facility in our state for the assessment and management of such patients due to which many such patients are brought to our clinic. Another reason could be the awareness generated by our department about autism and related disorders through regular seminars and print and mass media and thus increased referral of such patients from doctors and general public to our clinic. About $65 \%$ of children with ASDs in our study were below 6 years with about 53\% in age group 4-6 years. Our results are consistent with other studies from India and abroad which have reported the mean age of presentation 3.5 to 4.5 years [38,39]. A thorough review on early diagnosis of ASDs revealed many children with ASDs in first year of their life exhibit some recognizable problems in social interactions [40]. Current knowledge about developmental difficulties among children with ASDs has made it possible to identify the condition very early in their life for a 
substantial proportion. Despite the growing awareness of ASDs and our ability to identify the signs of ASDs early in life, studies have found that these children do not receive a diagnosis until they have attained a school age [41-43]. This is further complicated by paucity of trained professionals for the diagnosis of ASD. In an attempt to develop a screening instrument to screen ASDs on a large scale in north Indian Hindi speaking population by multipurpose health workers, Arun and Chavan found Chandigarh Autism Screening Instrument to be a valid instrument but suggested to evaluate its usefulness in larger community study [44]. Although early diagnosis of ASDs is critical for many reasons, but the most important reason is to start early intervention in these children to improve their functioning as these may be more effective with younger children $[45,46]$. There is an evidence suggesting that early interventions enhance long term prognosis and as a child gets older these interventions yield diminishing results $[18,47]$. Many studies have found that the functional gains associated with early intervention will result in significant cost savings to both families of children with ASDs and the settings in which they are served $[48,49]$. To provide consensus guidelines on evaluation and management of ASDs in children in India, Dalwai et. al. recommended that a definitive diagnosis is not necessary for commencing intervention which should begin as early as possible targeting core features of autism with intervention being specific, evidence-based, structured and appropriate to the developmental needs of the child [50]. They further recommended that management of these children should be provided through interdisciplinary teams, coordinated by the Pediatrician [50]. $78.18 \%$ in our study were males and male to female ratio was 3.58:1. With regard to sex and ASDs, studies have reported two consistent findings. Firstly, male predominance for ASDs with an approximate sex ratio of four to one across the whole spectrum, with a rise in ratio to eight or nine to one in higher functioning ASDs children [13,51]. Secondly, on average, females with ASDs identified clinically, have lower intelligence than males with ASDs [52,53]. Since there is inverse relationship between symptoms of ASDs and IQ, intelligence acts as a potential confounding factor in studies on sex differences in ASDs, emphasizing the need to control for its effects [53,54]. However, a bias for male predominance could not be ruled out in our study as the studies have found a gender based differential help seeking in childhood psychiatric disorders due to the importance given to boys in India [55,56]. The family characteristics showed that $52.73 \%$ of the families were of nuclear type. High proportion of nuclear families in this study can be explained by 2011 census of Jammu and Kashmir which showed the occurrence of the nuclear families as $73 \%$ and extended families as $13.5 \%$ [57]. Majority of the patients (63.63\%) belonged to rural area which can be explained by the overall rural and urban division of the population in our state where still the majority of the population resides in rural areas [57]. In our study we found about $70 \%$ of children with ASDs were staying at home and rest were students with only about $5.5 \%$ of them in regular schools. As most of these children were in lower age group, it is expected many of these to be staying at home, but the numbers of ASDs cases in special school or regular school were low. Although international and national organizations are increasingly advocating inclusive education for students with disabilities globally, but in many countries including India these children do not even attend schools, let alone a special one [58-61]. In developing countries including India, the implementation of inclusive education of children with disabilities including ASDs is basically undertaken by the non-government organizations (NGOs) instead of a country's government [62]. Similar findings have been mentioned in the studies of Alur $[63,64]$. It is very unfortunate and disappointing that the role of governments seems to be limited to the formulation or changing of education policies for these children and the initiatives in implementing these policies at grass-roots level is left to local or international NGOs [62]. Furthermore, there are many challenges in implementing inclusive education. Lack of trained resource persons or special educators in government and government aided schools remains a major challenge and if the trained staff exists somewhere, most of them are trained to handle children with special needs in general, hence compromising and overlooking the specific needs of children with ASDs [65]. In addition, many such schools do not feel equipped to include children with ASDs in the regular classroom, instead having them in separate sections, thereby defeating the very purpose of an inclusive education [65]. As a result, most children with ASDs remain in privately run special needs settings, which continue to mushroom to fill the gaping absence of inclusive educational opportunities. There is no body for the standardization of services or monitoring of the quality of education across institutions. It would be fair to state that most children with ASDs continue to be out of school or in inadequately equipped places [65]. Unless there are no sincere efforts for inclusive education from Government, things are going to worsen further for the children with ASDs. With regard to DSM IV-TR sub classification, about $62 \%$ cases were Autism and $31 \%$ cases were PDD-NOS. A review article on prevalence of ASDs, including autistic disorder, AS, PDDNOS, and CDD found that, in comparison to autistic disorder and PDD-NOS, prevalence for AS was much lower and that the CDD was a rarity as a disorder [15]. The results of this review on epidemiological studies of ASDs are reflected in hospital based studies, including our study which have shown autistic disorder and PDD-NOS being more frequent diagnosis and Asperger disorder being diagnosed at a much lower rate whereas CDD diagnosed rarely [66]. About $85.45 \%$ of our subjects had comorbid mental retardation. A hospital based study by Karl V et al. found that $95 \%$ of children with autism had co-morbid mental retardation [67]. Epidemiological surveys also indicate that approximately $70 \%$ of autism cases have significant mental retardation $[68,69]$. To conclude our study, $10.4 \%$ of children and adolescents with psychiatric disorders were having ASDs with autistic disorder and PDD NOS representing more than $90 \%$ of these cases. Despite the growing global attention for inclusive education to these children, only $3 \%$ of our cases were receiving inclusive education and about $70 \%$ of cases were staying at home. There is need to work on the lines of west for inclusive education of children with PDDs and need to start changing laws and regulations, adapt teacher education, empower parents and do all the other sensible things the West has done. 


\section{Limitations}

Our study should be viewed with following limitations in mind: Due to its cross sectional nature, changes over time can't be

\section{References}

1 Volkmar FR, Reichow B, McPartland J (2012) Classification of autism and related conditions: progress, challenges, and opportunities. Dialogues Clin Neurosci 14: 229.

2 Ozonoff S, Heung K, Byrd R, Hansen R, Hertz-Picciotto I (2008) The onset of autism: patterns of symptom emergence in the first years of life. Autism Res 1: 320-328.

3 Barbaro J, Dissanayake C (2009) Autism spectrum disorders in infancy and toddlerhood: a review of the evidence on early signs, early identification tools, and early diagnosis. J Dev Behav Pediatr 30: 447-459.

4 Yirmiya N, Charman T (2010) The prodrome of autism: early behavioral and biological signs, regression, peri-and post-natal development and genetics. J Child Psychol Psychiatry 51: 432-458.

5 Lauritsen MB (2013) Autism spectrum disorders. Eur Child Adolesc Psychiatry 22: 37-42.

6 Rogers SJ (2009) What are infant siblings teaching us about autism in infancy? Autism Res 2: 125-137.

7 Pisula E (2000) Pervasive developmental disorders: controversies concerning the classification of autism. Psychiatr Pol 34: 447-455.

8 Volkmar FR, McPartland JC (2014) From Kanner to DSM-5: autism as an evolving diagnostic concept. Annu Rev Clin Psychol 10: 193-212.

9 Raina SK, Kashyap V, Bhardwaj AK, Kumar D, Chander V (2015) Prevalence of autism spectrum disorders among children (1-10 years of age)-Findings of a mid-term report from Northwest India. J Postgrad Med 61: 243.

10 Walker DR, Thompson A, Zwaigenbaum L, Goldberg J, Bryson SE, et al. (2004) Specifying PDD-NOS: a comparison of PDD-NOS, Asperger syndrome, and autism. J Am Acad Child Adolesc Psychiatry 43: 172 180.

11 Witwer AN, Lecavalier L (2008) Examining the validity of autism spectrum disorder subtypes. J Autism Dev Disord 38: 1611-1624.

12 Sharma S, Woolfson LM, Hunter SC (2012) Confusion and inconsistency in diagnosis of Asperger syndrome: a review of studies from 1981 to 2010. Autism 16: 465-486.

13 Baird G, Simonoff E, Pickles A, Chandler S, Loucas T, et al. (2006) Prevalence of disorders of the autism spectrum in a population cohort of children in South Thames: The Special Needs and Autism Project (SNAP). Lancet 368: 210-215.

14 Fombonne E (1999) The epidemiology of autism: a review. Psychol Med 290: 769-786.

15 Fombonne E (2009) Epidemiology of pervasive developmental disorders. Pediatr Res 65: 591.

16 Jaisoorya TS, Jacob P, Srinath S, Kumar S, Manoj L, et al. (2018) Toddlers at risk for Autism Spectrum Disorders from Kerala, India-A community based screening. Asian J Psychiatr 31: 10-12. discerned. Sample size was small. Only outpatient children and adolescents with ASDs were included which limit the generalizability of our results. Control group for comparison was not there and the clinical information collected was little.

17 Kumar A, Juneja M, Mishra D (2016) Prevalence of autism Spectrum disorders in siblings of Indian children with autism Spectrum disorders. J Child Neurol 31: 873-878.

18 Lord C (1995) Follow-up of two-year-olds referred for possible autism. J Child Psychol Psychiatry 36: 1365-1382.

19 Dsm-Iv-tr AP (2000) Diagnostic and statistical manual of mental disorders-text revision. Washington, DC: American Psychiatric Association.

20 Volkmar FR, Carter A, Grossman J, Klin A (1997) Social development in autism. Handbook of autism and pervasive developmental disorders 2: 173-194.

21 Walters AS, Barrett RP, Feinstein C (1990) Social relatedness and autism: current research, issues, directions. Res Dev Disabil 11: 303 326.

22 Wing L, Gould J (1979) Severe impairments of social interaction and associated abnormalities in children: epidemiology and classification. J Autism Dev Disord 9: 11-29.

23 Dawson G, Osterling J (1997) Early intervention in autism. In: The effectiveness of early intervention (Guralnick MJ Edn). Baltimore: Brookes, Pp: 307-326.

24 Smith B, Chung MC, Vostanis P (1994) The path to care in autism: Is it better now? J Autism Dev Disord 24: 551-563.

25 Siegel BR, Pliner CA, Eschler JA, Elliott GR (1988) How children with autism are diagnosed: difficulties in identification of children with multiple developmental delays. J Dev Behav Pediatr 9: 199-204.

26 Sparks BF, Friedman SD, Shaw DW, Aylward EH, Echelard D, et al. (2002) Brain structural abnormalities in young children with autism spectrum disorder. Neurology 59: 184-192.

27 Wong VC, Hui SL (2008) Epidemiological study of autism spectrum disorder in China. J Child Neurol 23: 67-72.

28 Elsabbagh M, Divan G, Koh YJ, Kim YS, Kauchali S, et al. (2012) Global prevalence of autism and other pervasive developmental disorders. Autism Res 5: 160-179.

29 WHO (1993) The ICD-10 classification of mental and behavioural disorders: diagnostic criteria for research. World Health Organization.

30 Kalra V, Seth R, Sapra S (2005) Autism-experiences in a tertiary care hospital. Indian J Pediatr 72: 227-230.

31 Malhi P, Singhi P (2014) A retrospective study of toddlers with autism spectrum disorder: clinical and developmental profile. Ann Indian Acad Neurol 17: 25

32 Divan G, Vajaratkar V, Desai MU, Strik-Lievers L, Patel V (2012) Challenges, coping strategies, and unmet needs of families with a child with autism spectrum disorder in Goa, India. Autism Res 5: 190200.

33 Patra S, Arun P (2011) Use of Indian scale for assessment of autism in child guidance clinic: an experience. Indian J Psychol Med 33: 217. 
34 Chaudhury S, Prasad PL, Zacharias R, Madhusudan T, Saini R (2007) Psychiatric morbidity pattern in a child guidance clinic. Med J Armed Forces India 63: 144-146.

35 Nawarathna SC, Subba SH, Guha A (2016) Clinico-epidemiological profile of psychiatric disorders among children in a tertiary care hospital of Southern India. J Clin Diagn Res 10: VC05-VC08.

36 Tulachan P, Chapagain M, Kunwar AR, Sharma VD (2014) Psychiatric morbidity pattern in a child and adolescent guidance clinic. J Psychiat Assoc Nepal 1: 20-3.

37 Staller JA (2006) Diagnostic profiles in outpatient child psychiatry. Am J Orthopsychiatry 76: 98-102.

38 Juneja M, Sharma S, Mukherjee SB (2010) Sensitivity of the autism behavior checklist in Indian autistic children. J Dev Behav Pediatr 31 48-49.

39 Landa RJ (2008) Diagnosis of autism spectrum disorders in the first 3 years of life. Nat Clin Pract Neurol 4: 138-147.

40 Charman T, Baird G (2002) Practitioner review: Diagnosis of autism spectrum disorder in 2-and 3-year-old children. J Child Psycho Psychiatry 43: 289-305.

41 Howlin P (1997) Prognosis in autism: do specialist treatments affect long-term outcome? Eur Child Adolesc Psychiatry 6: 55-72.

42 Levy SE, Mandell DS, Merhar S, Ittenbach RF, Pinto-Martin JA (2003) Use of complementary and alternative medicine among children recently diagnosed with autistic spectrum disorder. J Dev Behav Pediatr 24: 418-423.

43 Yeargin-Allsopp M, Rice C, Karapurkar T, Doernberg N, Boyle C, et al. (2003) Prevalence of autism in a US metropolitan area. JAMA 289: 49-55.

44 Arun P, Chavan BS (2018) Development of a screening instrument for autism spectrum disorder: Chandigarh Autism Screening Instrument. Indian J Med Res 147: 369.

45 Campbell M, Schopler E, Cueva JE, Hallin A (1996) Treatment of autistic disorder. J Am Acad Child Adolesc Psychiatry 35: 134-143.

46 Volkmar F, Cook EH, Pomeroy J, Realmuto G, Tanguay P (1999) Practice parameters for the assessment and treatment of children, adolescents, and adults with autism and other pervasive developmental disorders. J Am Acad Child Adolesc Psychiatry 38: 32S-54S.

47 Mars AE, Mauk JE, Dowrick PW (1998) Symptoms of pervasive developmental disorders as observed in prediagnostic home videos of infants and toddlers. J Pediatr 132: 500-504.

48 Jacobson JW, Mulick JA, Green G (1998) Cost-benefit estimates for early intensive behavioral intervention for young children with autism-general model and single state case. Behav Interv 13: 201226.

49 Jacobson JW, Mulick JA (2000) System and cost research issues in treatments for people with autistic disorders. J Autism Dev Disord 30: 585-593.

50 Dalwai S, Ahmed S, Udani V, Mundkur N, Kamath SS, et al. (2017) Consensus statement of the Indian academy of pediatrics on evaluation and management of autism spectrum disorder. Indian Pediatr 54: 385-393.

51 Mandy W, Charman T, Gilmour J, Skuse D (2011) Toward specifying pervasive developmental disorder-not otherwise specified. Autism Res 4: 121-131.

52 Lord C, Schopler E (1985) Brief report: differences in sex ratios in autism as a function of measured intelligence. J Autism Dev Disord 15: 185-193.

53 Volkmar FR, Szatmari P, Sparrow SS (1993) Sex differences in pervasive developmental disorders. J Autism Dev Disord 23: 579 591.

54 Skuse DH, Mandy W, Steer C, Miller LL, Goodman R, et al. (2009) Social communication competence and functional adaptation in a general population of children: preliminary evidence for sex-byverbal IQ differential risk. J Am Acad Child Adolesc Psychiatry 48: 128-137.

55 Haub C, Sharma OP (2006) India's population reality: reconciling change and tradition. Popul Bull 61: 1-20.

56 Arnold F, Choe MK, Roy TK (1998) Son preference, the familybuilding process and child mortality in India. Popul Stud 52: 301-315.

57 http://planningcommission.nic.in/data/datatable/data_2312/ DatabookDec2014\%20307.pdf

58 Armstrong D, Armstrong AC, Spandagou I (2011) Inclusion: by choice or by chance? Int J Inclusive Educ 15: 29-39.

59 Engelbrecht $P$ (2006) The implementation of inclusive education in South Africa after ten years of democracy. Eur J Psychol Educ 21: 253-264.

60 Singal N (2006) An ecosystemic approach for understanding inclusive education: An Indian case study. Eur J Psychol Educ 3: 239-252.

61 Srivastava M, de Boer AA, Pijl SJ (2015) Know how to teach me... Evaluating the effects of an in-service training program for regular school teachers toward inclusive education. Int J Sch Educ Psychol 3: 219-230.

62 Srivastava M, de Boer A, Pijl SJ (2015) Inclusive education in developing countries: a closer look at its implementation in the last 10 years. Educ Rev 67: 179-195.

63 Alur M (2002) They did not figure: policy exclusion of disabled people in India. Int J Inclusive Educ 6: 101-112.

64 Alur M (2008) The lethargy of a nation: Inclusive education in India and developing systemic strategies for change. In: Policy, experience and change: Cross-cultural reflections on inclusive education. Springer, Dordrecht. Pp: 91-106.

65 Barua M, Kaushik JS, Gulati S (2017) Legal provisions, educational services and health care across the lifespan for autism spectrum disorders in India. Indian J Pediatr 84: 76-82.

66 Harstad EB, Fogler J, Sideridis G, Weas S, Mauras C, et al. (2015) Comparing diagnostic outcomes of autism spectrum disorder using DSM-IV-TR and DSM-5 criteria. J Autism Dev Disord 45: 1437-1450.

67 Kalra V, Seth R, Sapra S (2005) Autism-experiences in a tertiary care hospital. Indian J Pediatr 72: 227-230.

68 Chakrabarti S, Fombonne E (2005) Pervasive developmental disorders in preschool children: confirmation of high prevalence. Am J Psychiatry 162: 1133-1141.

69 Honda H, Shimizu Y, Imai M, Nitto Y (2005) Cumulative incidence of childhood autism: a total population study of better accuracy and precision. Dev Med Child Neurol 47: 10-18. 